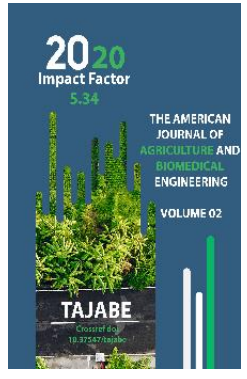

Copyright: Original content from this work may be used under the terms of the creative commons attributes 4.0 licence.

\section{The Quality Of Potato Tubers For The Preparation Of Chips, Depending On The Growing Time And Elements Cultivation Technology}

\author{
Ibragim.Tashkentovich. Ergashev \\ Samarkand Institute Of Veterinary Medicine, Samarkand, Uzbekistan \\ Ilkhom. Bakhtiyorovich. Begimkulov \\ Samarkand Institute Of Veterinary Medicine, Samarkand, Uzbekistan
}

\title{
ABSTRACT
}

The article presents data on the study of the influence of varietal characteristics, timing of growing potatoes and plant placement patterns on the yield and quality of potato chips. It was established that tubers of the Ramona variety are more suitable than Surkhan-1 because of the content of more dry matter and starch. It is noted that during spring planting and with a sparse planting pattern of seed tubers, the tubers contain more dry matter and starch. This contributes to a higher yield and quality of the prepared chip.

\section{KEYWORDS}

Potato, tubers, dry matter, starch, vitamin C, sugar, chip yield, chip quality, etc.

\section{INTRODUCTION}

In Uzbekistan, in recent years, much attention has been paid to the processing of potatoes, including in the direction of the preparation of the chip for which the quality of the tubers is essential.
It is known that the quality of potatoes depends on many factors, among which the main ones are the characteristics of the variety, soil and climatic conditions, elements of the technology of cultivation, etc. 
The main quality indicators of potato tubers are the content of dry matter, starch, protein, vitamin C, and total sugar in the tubers. Of these, the most important determining the nutritional value of the prepared chip is carbohydrates and, first of all, starch which accounts for $95-99 \%$ of the total carbohydrate content in tubers. [1].

In literature there is information about the variability of starch, sugar, water-soluble proteins and vitamin $C$, depending on various factors. Therefore, the study of the influence of these factors on the biochemical composition of potato tubers and the quality of chips in each particular region is of great relevance.

\section{THE PURPOSE OF RESEARCH}

The studies were carried out in order to study the varietal characteristics and the impact of some organizational and agricultural measures on the biochemical composition of potato tubers, the yield and quality of the chips prepared from them.

\section{MATERIALS AND METHODS}

Field experiments were laid in 2018-2019 at the experimental site of the Samarkand experimental station of the research institute of vegetable and melon crops and potatoes. Spring planting was carried out at the beginning of March, harvesting in the month of June, summer planting was carried out in midJuly, and harvesting in the month of October. We studied options for planting seed tubers according to the scheme $70 \times 15,70 \times 20$ and $70 \times 25 \mathrm{~cm}$.

Laboratory analyzes were carried out in the laboratories of the Department of Technology, Storage, Processing of Crop and Livestock Products and of the Department of Crop and Feed Production of the Samarkand Institute of Veterinary Medicine. The quality of potato chips was determined by the method of M.A. Nikolayeva (2000). Statistical data processing was carried out according to the program Microsoft Office Exel 2010 and Statlstica 13.3.

\section{RESEARCH RESULTS}

Studies have established that potato yields are largely dependent on varietal characteristics, growing times and tuber planting patterns. For example, a medium-early variety of potato Ramona obtained high yields in comparison with the early ripening variety Surkhan-1. So, with a spring planting with a planting pattern of $70 \times 15 \mathrm{~cm}$. the yield of Surkhan-1 varieties was $24.1 \mathrm{t} / \mathrm{ha}$, and for Ramona cultivar at this planting date, with the same plant placement scheme, $26.3 \mathrm{t}$ were obtained per unit area. tubers. It should be noted that in both studied varieties the highest yield was obtained in the variant with a planting scheme of $70 \times 20 \mathrm{~cm}$. This trend continues for the summer landing period. For example, during spring planting according to the planting scheme of $70 \times 20 \mathrm{~cm}$, 26.5 tons were obtained from Surkhan-1 potato variety and 30.8 tons from Ramona variety. the crop. With an increase in the planting pattern, an increase in the yield of large tubers is observed due to a decrease in the proportion of small tubers.

It can be seen from the table that in summer planting higher yields were obtained compared to spring planting. For example, during spring planting, the yield of Surkhan-1 potatoes, depending on the plant layout, was 24.1-26.6 t / ha, and during the summer planting period, 26.2-28.7 t. respectively. The potato variety Ramona obtained similar results. This is due to the fact that in the conditions of Uzbekistan during spring planting, the period of potato tuberization coincides with relatively high air temperatures, which negatively affects the growth and development of potatoes - a temperate climate culture.

It is known that the quality of potato tubers for processing, including for the preparation of chips, depends on the biochemical composition of the tubers, especially the 
The American Journal of Agriculture and Boimedical Engineering (ISSN - 2689-1018)

Published: October 28, 2020 | Pages: 38-45

Doi: https://doi.org/10.37547/tajabe/Volume02Issue10-07

content of dry matter, starch, vitamin $C$ and sugar in them. Given these circumstances, in our studies we performed laboratory analyzes of tubers in the studied varieties obtained from different cultivation periods and seed tuber planting patterns. Studies have established that the dry matter content in potato tubers depends on varietal characteristics. For example, the medium early variety Ramona contains more dry solids than the variety Surkhan-1, so that if the variety Surkhan-1, depending on the growing time and planting patterns, the tubers contained $19.0-21.2 \%$ of dry matter, then the variety Ramona, this figure is 20.5-22.9\%, respectively. This indicates that when selecting a variety for the processing of tubers, it is necessary to take into account the characteristics of the variety. In addition, it should be noted that tubers grown in spring contain more starch than summer planting. For example, in the Surkhan-1 variety, depending on the planting patterns of seed tubers, the starch content was 20.4-21.2\%, and in summer growing periods of $19.0-19.9 \%$, respectively. Variety Ramona obtained similar results.

It has been established that agrotechnical measures may have a small effect on the solids content in potato tubers. For example, in the Surkhan-1 variety, during spring planting with a planting scheme of $70 \times 15 \mathrm{~cm}$, tubers contained $24.1 \%$, and with a scheme of $70 \times 20 \mathrm{~cm}-20.7 \%$, and with a planting scheme of plants $70 \times 25 \mathrm{~cm}$, $21.2 \%$ dry matter. The Ramona variety obtained similar results and these indicators were 21.6 $22.9 \%$, respectively (table-1).

\section{Table-1}

The yield and quality of potato tubers, depending on the variety, growing dates and plant layout (2018-2019)

\begin{tabular}{|c|c|c|c|c|c|c|}
\hline \multicolumn{2}{|c|}{ Experience Options } & \multirow{2}{*}{$\begin{array}{c}\text { Productivity, } \\
\text { t/ ha }\end{array}$} & \multicolumn{4}{|c|}{ The content in the tubers,\% } \\
\hline landing dates & $\begin{array}{c}\text { landing } \\
\text { pattern, } \\
\mathrm{cm}\end{array}$ & & $\begin{array}{c}\text { dry } \\
\text { matter }\end{array}$ & starch & $\begin{array}{c}\text { vitamin } \\
\text { c,\% mg / } \\
\text { kg }\end{array}$ & $\begin{array}{l}\text { total } \\
\text { sugar }\end{array}$ \\
\hline
\end{tabular}

\begin{tabular}{|c|c|c|c|c|c|c|}
\hline \multicolumn{7}{|c|}{ Variety Surkhan-1 } \\
\hline \multirow{3}{*}{$\begin{array}{c}\text { Spring } \\
\text { planting }\end{array}$} & $70 \times 15$ & 24,1 & 20,4 & 14,1 & 10,1 & 0,84 \\
\hline & $70 \times 20$ & 26,5 & 20,7 & 14,5 & 9,8 & 0,76 \\
\hline & $70 \times 25$ & 22,3 & 21,2 & 15,1 & 9,6 & 0,70 \\
\hline \multirow{3}{*}{$\begin{array}{c}\text { Summer } \\
\text { planting with } \\
\text { freshly } \\
\text { harvested } \\
\text { tubers }\end{array}$} & $70 \times 15$ & 26,2 & 19,0 & 13,8 & 10.7 & 0,91 \\
\hline & $70 \times 20$ & 28,7 & 19,4 & 14,0 & 10,2 & 0,96 \\
\hline & $70 \times 25$ & 27,1 & 19,9 & 14,3 & 9,3 & 1,01 \\
\hline \multicolumn{7}{|c|}{ Variety Ramona } \\
\hline & $70 \times 15$ & 26,3 & 21,6 & 17,1 & 10,0 & 0,75 \\
\hline
\end{tabular}


The American Journal of Agriculture and Boimedical Engineering (ISSN - 2689-1018)

\begin{tabular}{|c|c|c|c|c|c|c|}
\hline \multirow{2}{*}{$\begin{array}{c}\text { Spring } \\
\text { planting }\end{array}$} & $70 \times 20$ & 30,8 & 22,2 & 17,4 & 9,7 & 0,72 \\
\cline { 2 - 7 } & $70 \times 25$ & 28,5 & 22,9 & 17,9 & 9,4 & 0,68 \\
\hline \multirow{3}{*}{$\begin{array}{c}\text { Summer } \\
\text { planting with } \\
\text { freshly } \\
\text { harvested } \\
\text { tubers }\end{array}$} & $70 \times 15$ & 28,3 & 20,5 & 15,6 & 10,8 & 0,91 \\
\cline { 2 - 7 } & $70 \times 25$ & 30,8 & 21,3 & 16,4 & 10,3 & 0,82 \\
\hline
\end{tabular}

During the summer planting with freshly harvested tubers in both studied varieties, a decrease in the dry matter content was noted in comparison with the spring growing period. In the tubers of Surkhan-1 variety in the spring planting period, the dry matter content ranged from $20.4-21.2 \%$, and in the summer cultivation period, the value of this indicator was Ramona varieties; these indicators were 21.6-22.9 and $20.5-21.3 \%$ respectively.

The data obtained indicate that during summer planting, plant vegetation, especially the tuber formation period, occurs at a relatively low air temperature compared to the spring planting period, which contributes to a decrease in the dry matter content in tubers. At higher air temperatures, the solids content in tubers increases both in the early-ripening Surkhon-1 variety and in the medium-early Ramon potato variety.

As you know, the starch content in tubers is one of the important indicators of their suitability for processing for which they are used. Our studies have shown that there is a direct correlation between the dry matter and starch content in potato tubers, i.e. the more dry matter, the more starch is contained.

It was established that in the tubers of the midearly variety of Ramon potatoes, the tubers contain more starch compared to the early ripening variety Surkhan-1. So, if the content of starch in the tubers of Ramona varieties was 15.6-17.9\%, depending on the cultivation period and seed tuber planting patterns, when in Surkhan-1 varieties these indicators were in the range of $14.0-15.1 \%$.

Our studies have shown that in the conditions of Uzbekistan for the selection of varieties for processing potato tubers, it is necessary to take into account the organizational and agricultural measures used. So, the cultivation of potatoes during spring planting contributes to the accumulation of a large amount of starch. For example, in Surkhan-1 variety in this cultivation period, the starch content in potato tubers was 14.1-15.1\%, depending on the planting patterns of seed tubers. In the Ramona variety, this indicator is $17.1-17.9 \%$, respectively. During summer planting with freshly harvested tubers, a slight decrease in starch content in tubers is observed. This trend is observed in both studied varieties.

Such results are apparently associated with high summer air temperatures which coincides with the period of potato tuberization. And in more favorable climatic conditions for potatoes, a decrease in the starch content in tubers is observed.

In addition, it was found that some elements of the technology may affect the starch content in potato tubers. This applies to both spring planting and summer planting freshly harvested. For example, in Surkhan-1 variety, during spring planting with a planting pattern of $70 \times 15 \mathrm{~cm}, 14.1 \%$ of starch accumulated in tubers in tubers, when according to the plant layout scheme $70 \times 25 \mathrm{~cm}$ this indicator is $15.1 \%$. 
The American Journal of Agriculture and Boimedical Engineering (ISSN - 2689-1018)

During summer planting with freshly harvested tubers, these indicators were 13.8 and $14.3 \%$, respectively.

Variety Ramona obtained similar results. The starch content in the tubers was 17.1 and $17.9 \%$ and 15.6 and $16 \%$, depending on the timing of cultivation and plant placement patterns.

The data obtained allow us to conclude that, for the processing of tubers due to the starch content, the most suitable are potato tubers obtained from the spring planting dates grown according to the sparse cultivation scheme.

The vitamin $C$ content in potato tubers is one of the important indicators for determining the palatability of cooked products, i.e. chips. Given these circumstances, in our studies, we studied the influence of cultivation timelines and plant placement patterns not on the content of vitamin $C$ in potato tubers.

Studies have shown that Ramona potato tubers contain more starch (9.4-10.8\% mg / kg) than Surkhan-1, which has a vitamin $C$ content of tubers of $9.3-10.7 \%$, depending on from the timing of cultivation and plant layout.

It should be noted that both studied varieties during summer planting with freshly harvested tubers contained more vitamin C compared to spring planting. In addition, there is an increase in the content of this vitamin $\mathrm{C}$ by thickening of crops. The results were obtained with both spring and summer planting with freshly harvested tubers. Similar results were obtained in both varieties studied.

Some authors note that, along with other indicators of the biochemical composition of tubers that are relevant for the processing of tubers for the preparation of chips, the content of total sugar in them is also significant. Given this information, in our studies, we conducted laboratory analyzes to determine the total sugar content in potato tubers, depending on the variety, the timing of growing the crop and the layout of the plants.

Studies have shown that the potato tubers of Surkhan-1 contain more sugar than Ramona. So, for example, in Surkhan-1 variety this indicator fluctuates within $0.70-0.96 \%$, when in Ramona variety tuber contains $0.68-0.91 \%$, depending on the timing of cultivation and plant placement patterns.

It should be noted that both varieties contain less sugar in potato harvests from spring planting dates compared to freshly harvested tubers obtained from summer crops.

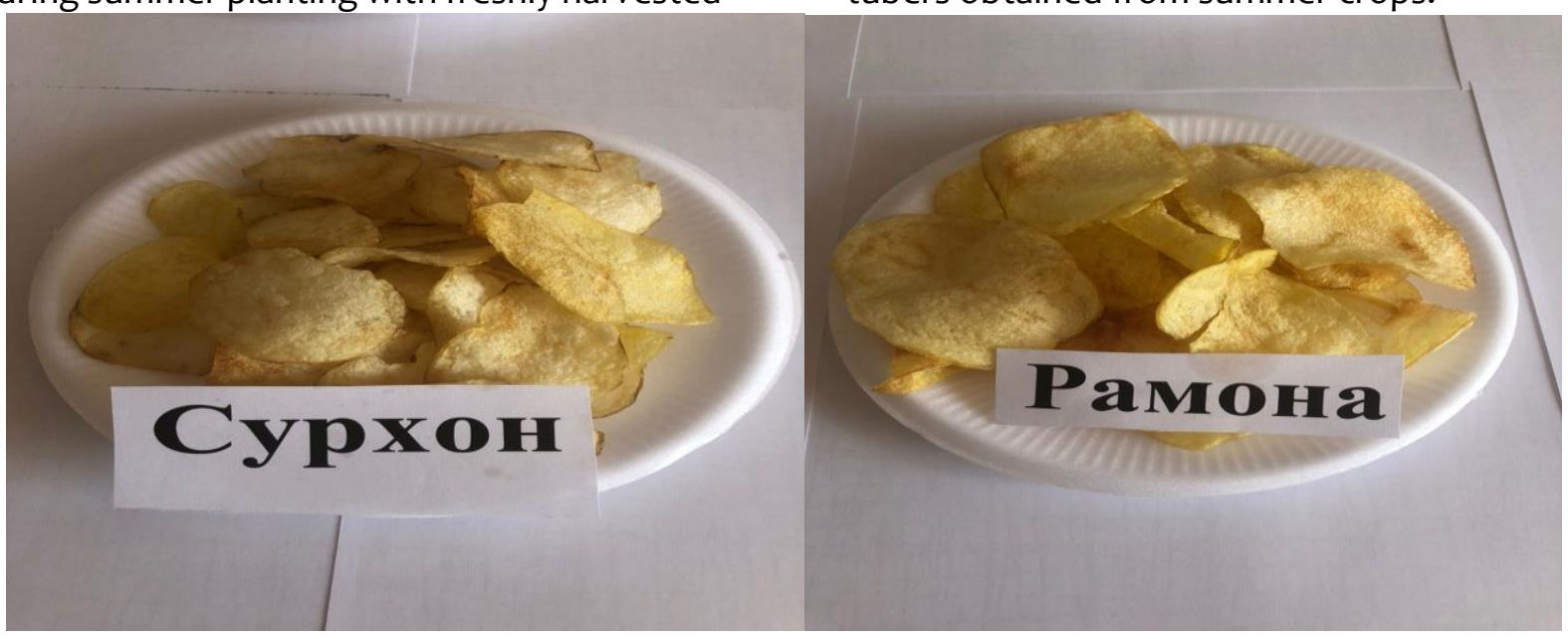

Picture 1. Chips made from tubers of varieties Surkhan-1 and Ramona 
It was established that with plant thickening, a slight increase in the total sugar content in potato tubers was noted. For example, in springtime, the cultivars of Surkhan-1 varieties with a planting pattern of $70 \times 15 \mathrm{~cm}$ contain $0.84 \%$ sugar in potato tubers, and in the $70 \times 25$ $\mathrm{cm}$ variant this figure is $0.70 \%$. Similar data were obtained for summer planting with freshly harvested tubers. The same data were obtained from the potato variety Ramona.

Both studied varieties have more sugar in the tubers during the summer planting season compared to the spring planting season. For example, if the potato cultivar Surkhan-1 during spring planting according to the planting scheme of $70 \times 20 \mathrm{~cm}$ in tubers contains $0.76 \%$ sugar, then in tubers from the summer planting dates according to the same planting scheme this indicator is $0.96 \%$. In the Ramona potato variety, these indicators were 0.75 and $0.85 \%$, respectively.
The data obtained are apparently due to the physiological immaturity of the tubers from the summer terms for planting potatoes with freshly harvested tubers.

We carried out studies to determine the quality of the chip prepared from tubers of potatoes grown from different varieties, the timing of cultivation with different plant layouts. It was established that the yield and quality of the resulting chip depends on the varietal features and technologies of potato cultivation. In the Ramon variety, the yield of the chip and its quality was high compared to the Surkhan-1 variety. For example, in Ramona tubers, the yield of chips is $39,6-41,9 \%$, depending on the timing of planting of plant placement schemes, when Surkhan-1, these indicators were 38,4$39,0 \%$, respectively (table 2 ).

\section{Table 2}

The yield and quality of potato chips, depending on the timing of cultivation and plant layout

\begin{tabular}{|c|c|c|c|c|c|}
\hline \multicolumn{2}{|c|}{ Experience options } & \multirow{2}{*}{$\begin{array}{l}\text { The number of } \\
\text { tubers, grams }\end{array}$} & \multicolumn{2}{|c|}{ Chips output } & \multirow{2}{*}{$\begin{array}{l}\text { The quality of } \\
\text { the resulting } \\
\text { chips, score }\end{array}$} \\
\hline $\begin{array}{l}\text { Landing } \\
\text { time }\end{array}$ & $\begin{array}{c}\text { Landing } \\
\text { pattern, } \\
\mathrm{cm}\end{array}$ & & gram & $\%$ & \\
\hline \multicolumn{6}{|c|}{ Variety Surkhan-1 } \\
\hline
\end{tabular}


The American Journal of Agriculture and Boimedical Engineering (ISSN - 2689-1018)

Published: October 28, 2020 | Pages: 38-45

Doi: https://doi.org/10.37547/tajabe/Volume02Issue10-07

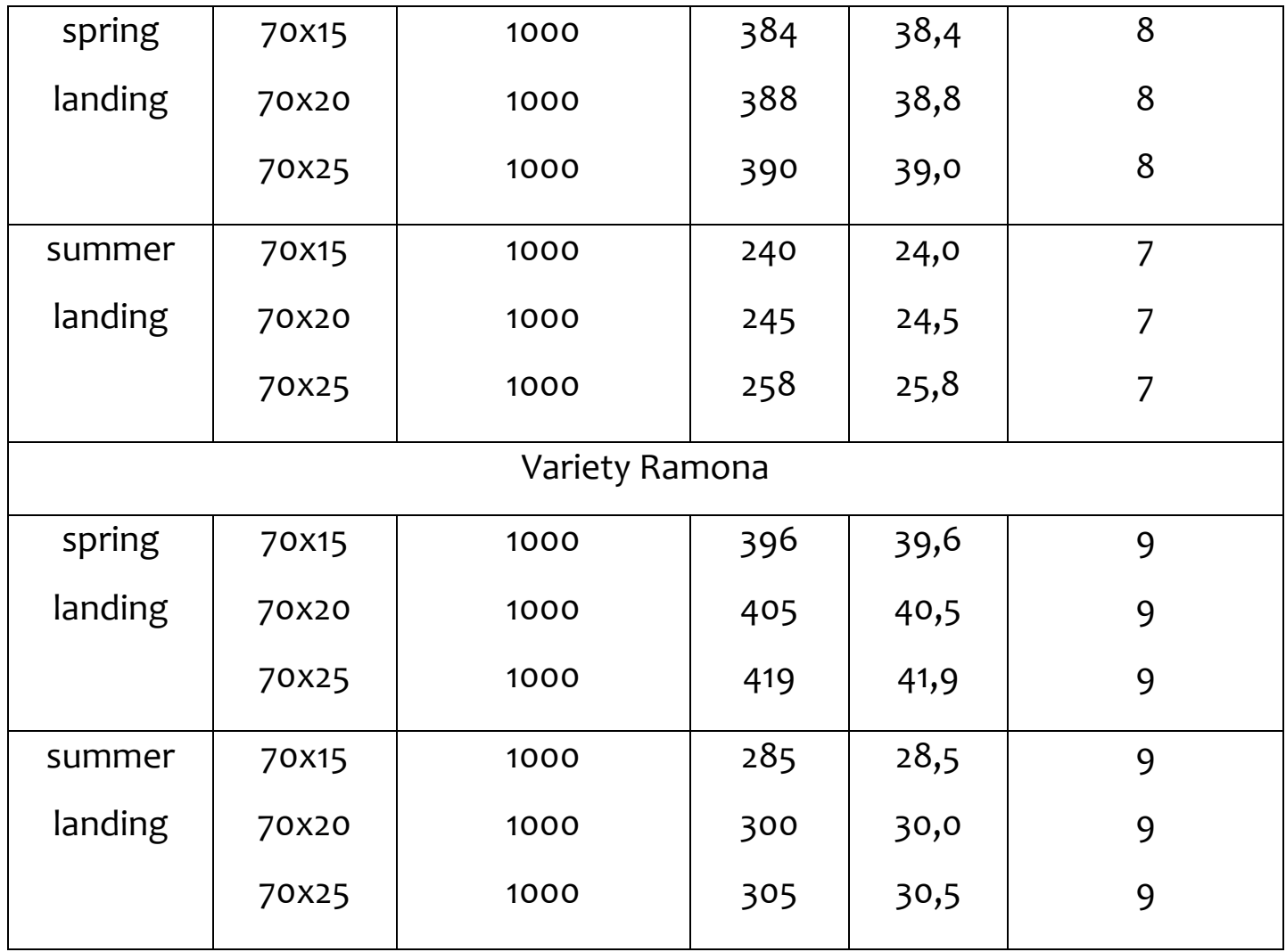

From table 2 it can be seen that the quality of the resulting chips from Surkhan-1 varieties depends on the growing time of the processed potatoes. So, the received products from spring planting was estimated at 8 points, when this indicator amounted to 7 points from the summer planting period. It should be noted that in the Ramona variety, the chips prepared from tubers from different

growing periods and plant placement schemes had the best qualities and were rated at 9 points.

\section{CONCLUSION}

The biochemical composition of the tubers and the quality of the prepared chips depend on the varietal characteristics of the culture, organizational and agricultural measures used in the cultivation of potatoes. Ramon potato tubers are more suitable for making quality chips. Potato tubers from spring plantings, according to a sparse planting pattern, contain more dry matter and starch than freshly harvested tubers compared to the summer planting period.

\section{REFERENCES}

1. Nikolaeva, M. A. Tovarovedenie potrebitelskix tovarov. Teoreticheskie osnovy: uchebnik dlya vuzov / M. A. Nikolaeva. - M. : NORMA Publishing House, 2000. - 283 p.

2. Nikolaeva, M. A. Xranenie prodovolstvennyx tovarov / M. A. Nikolaeva, G. Ya. Cutting. - M. : ID «FORUM»: INFRA-M, 2010. - 304 p.

3. Vsya pravda o kartofelnyx chipsax [Electronic register]. - Reaching mode: 
The American Journal of Agriculture and Boimedical Engineering (ISSN - 2689-1018)

Published: October 28, 2020 | Pages: 38-45

Doi: https://doi.org/10.37547/tajabe/Volume02Issue10-07

http://kp.ua/life/203395-vsia-pravda-okartofele-dlia-chypsov.

4. Ergashev I.T., Normurodov D.S., Eshonqulov B.M. Scientific basis of virusfree seed potato. Tashkent, 2017.165p.

5. Web sites: www.cripsproducts.com, www.wday.ru, www.biochemistry.com 